\section{Moving upstream in Huntington's}

\section{By Lauren Martz, Staff Writer}

Researchers at Harvard Medical School and The Scripps Research Institute each have published new strategies to treat Huntington's disease, a condition for which there is only one approved drug (see Table 1, Attacking Huntington's disease) ${ }^{1,2}$ The Harvard group showed that inhibiting cytochrome $\mathrm{C}$ release from the mitochondria might effectively combat the disease. The Scripps team described a more upstream approach-using histone deacetylase (HDAC) inhibitors to curb transcriptional dysregulation.

Companies and academics interviewed by SciBX had safety concerns about both approaches, but they think that if these issues are addressed, the strategies could be used together.

Huntington's disease (HD) is a neurodegenerative disorder caused by CAG repeats in the huntingtin (HTT) gene that manifest as a range of motor and cognitive defects. HTT is a 3,144 amino acid-long protein involved in many protein-protein interaction networks. ${ }^{3}$

Although $\mathrm{HD}$ is a monogenic disorder, the therapeutic challenge is posed by the myriad phenotypic effects that can culminate in neurodegeneration. Moreover, the exact route of pathogenesis is still ill defined. Known contributors - and thus potential points of therapeutic intervention-include transcriptional dysregulation, mitochondrial dysfunction, aberrant protein aggregation, excitotoxicity and disruptions in cellular trafficking. ${ }^{4}$

\section{Stop the apoptosis}

In a paper published in the Journal of Neuroscience, Robert Friedlander and colleagues at Harvard showed that intervention at the stage of mitochondrial dysregulation might provide neuroprotection. Friedlander is vice chairman of the Department of Neurosurgery and associate director of cerebrovascular surgery at Brigham and Women's Hospital.

Friedlander's team screened 1,040 neurological compounds on the market and in development by testing them on purified mitochondria. They identified 21 compounds that potently inhibited cytochrome $\mathrm{C}$ release. Of those, 16 also lowered cytochrome $\mathrm{C}$ release from mitochondria and lowered cell death in ST14A cells with mutated HTT.

The researchers chose one of the most potent compounds, methazolamide, for further analysis. Methazolamide is a generic approved to treat glaucoma.

Table 1. Attacking Huntington's disease. A number of companies are attempting to treat Huntington's disease (HD) by using different mechanisms. Some are targeting the disease by repairing the mutated protein responsible for the disease or eliminating its aggregation, whereas others are working further downstream at the points of mitochondria dysfunction, oxidative stress or excessive apoptosis, which all cause neuronal damage. Still other companies have compounds that protect or repair the neurons from the effects of the mutated protein. Selected compounds in development and on the market for HD are listed below.

\begin{tabular}{|c|c|c|c|c|}
\hline Category & Company & Product & Description & Status \\
\hline Aberrant apoptosis & $\begin{array}{l}\text { Neurologix Inc. } \\
\text { (OTCBB:NRGX) }\end{array}$ & dXIAP & $\begin{array}{l}\text { Mutated form of the gene } X \text {-linked inhibitor of } \\
\text { apoptosis (XIAP) delivered by adeno-associated virus } \\
\text { (AAV) vector }\end{array}$ & Preclinical \\
\hline \multirow[t]{3}{*}{ Neuroprotection } & $\begin{array}{l}\text { Ovation Pharmaceuticals Inc./ } \\
\text { Biovail Corp. (NYSE:BVF; TSX:BVF)/ } \\
\text { Cambridge Laboratories Ltd. }\end{array}$ & $\begin{array}{l}\text { Xenazine } \\
\text { tetrabenazine }\end{array}$ & $\begin{array}{l}\text { Selective inhibitor of vesicular monoamine } \\
\text { transporter } 2 \text { (VMAT2) }\end{array}$ & Marketed \\
\hline & NeuroSearch A/S (CSE:NEUR) & ACR16 & Dopamine stabilizer & Phase III \\
\hline & ReNeuron Group plc (LSE:RENE) & ReN005 & Neuronal stem cell transplantation & Preclinical \\
\hline \multirow[t]{2}{*}{$\begin{array}{l}\text { Mitochondrial } \\
\text { dysfunction }\end{array}$} & $\begin{array}{l}\text { Amarin Corp. plc (NASDAQ:AMRN)/ } \\
\text { Scil Group }\end{array}$ & $\begin{array}{l}\text { Miraxion } \\
(\text { AMR-101) }\end{array}$ & $\begin{array}{l}\text { Eicosapentaenoic acid derivative that inhibits } \\
\text { phospholipase } \mathrm{A}_{2}\left(\mathrm{PLA}_{2}\right) \text { and caspases }\end{array}$ & Phase III \\
\hline & $\begin{array}{l}\text { Medivation Inc. (NASDAQ:MDVN)/ } \\
\text { Pfizer Inc. (NYSE:PFE) }\end{array}$ & Dimebon & $\begin{array}{l}\text { Small molecule that blocks an undisclosed target } \\
\text { involving mitochondrial pores }\end{array}$ & Phase II \\
\hline \multirow[t]{2}{*}{ Mutated protein } & $\begin{array}{l}\text { Alnylam Pharmaceuticals Inc. } \\
\text { (NASDAQ:ALNY)/Medtronic Inc. } \\
\text { (NYSE:MDT) }\end{array}$ & ALN-HTT & $\begin{array}{l}\text { Small interfering RNA (siRNA) against the } \\
\text { huntingtin }(H T T) \text { gene delivered by Medtronic's } \\
\text { implantable infusion pump }\end{array}$ & Preclinical \\
\hline & $\begin{array}{l}\text { Targeted Genetics Corp. (NASDAQ:TGEN)/ } \\
\text { Merck \& Co. Inc. (NYSE:MRK) }\end{array}$ & siRNA/AAV1 & AAV vector delivering siRNA targeting $H T T$ & Preclinical \\
\hline Neuronal repair & Ceregene Inc. & CERE-120 & AAV Type 2 vector encoding neurturin (NTN) gene & Preclinical \\
\hline Oxidative stress & Avicena Group Inc. (Pink:AVCE) & HD-02 & $\begin{array}{l}\text { Therapeutic that incorporates a clinical form of } \\
\text { creatine }\end{array}$ & Phase II \\
\hline Protein aggregation & $\begin{array}{l}\text { Prana Biotechnology Ltd. (ASX:PBT; } \\
\text { NASDAQ:PRAN) }\end{array}$ & PBT2 & Metal protein-attenuating compound (MPAC) & Phase I \\
\hline
\end{tabular}


In HD cell lines, the drug inhibited release of both cytochrome $\mathrm{C}$ and the proapoptotic mitochondrial protein Smac/Diablo. In a mouse model of HD, methazolamide delayed disease onset, extended lifespan and lowered both cytochrome $\mathrm{C}$ release and neuronal death compared with the effects of saline controls.

"The release of cytochrome $\mathrm{C}$ occurs fairly early in the cell death process, so it is a good step to target," Friedlander told SciBX.

He added that many of the compounds addressed by the group's screening approach are already on the market for other indications. "These are FDA-approved drugs. We already know that methazolamide is safe and can cross the blood-brain barrier," Friedlander said.

"In theory, this is a shorter pathway to an approved compound for Huntington's disease treatment" compared with the discovery of new compounds, said Robert Pacifici, CSO of the CHDI Foundation Inc. "But it is important to look out for pitfalls. For example, minocycline, which is an approved antibiotic that was identified in the screen, was used in clinical testing for amyloid lateral sclerosis and the trials were halted because the compound was actually making people worse."

CHDI is a not-for-profit organization that supports the discovery and development of HD therapeutics.

Pacifici was also concerned that the compounds in the Journal of Neuroscience article might have effects on processes other than cytochrome $\mathrm{C}$ release. He noted that methazolamide is primarily a carbonic anhydrase inhibitor, so it has at least one other function.

Other researchers were concerned about the long-term effects of shutting off apoptosis in HD patients.

"There is concern that apoptosis is necessary to prevent cancer. Therefore, an increased risk of cancer could be an adverse effect" of an apoptosis inhibitor, said Ashley Bush, Australian Research Council Federation Fellow at the Mental Health Research Institute of Victoria and a founding scientist of Prana Biotechnology Ltd.

Prana's PBT2 is a metal protein-attenuating agent that blocks generation of reactive oxygen species and subsequent apoptosis. The compound has completed Phase I testing to treat HD.

David Rubinsztein, a professor of molecular neurogenetics at the University of Cambridge, agreed that cancer is a potential issue. "There is a chance that inhibiting apoptosis could increase the risk of cancer, and, with Huntington's disease, a long-term treatment is necessary, which could increase that risk," he said.

Potential safety issues aside, Pacifici questioned whether inhibiting apoptosis is the most efficacious way to treat HD. "You are preventing the neurons from dying, but it is not clear whether having a sick neuron is actually better than having a dead neuron," he said.

Friedlander's team showed that methazolamide delayed disease onset and extended lifespan by up to $27 \%$ and $20 \%$, respectively, in mice. He said the most important next step for his group is testing their findings in the clinic.

Belinda Tsao-Nivaggioli, chairman and CEO at Avicena Group Inc., agreed that clinical trials are the logical next step. "In Huntington's disease, if a therapeutic shows activity of increasing life by about $17-20 \%$ in preclinical models, it is usually worth moving forward into clinical testing," she said.
Avicena's HD-02, a therapeutic that incorporates a clinical form of creatine, has completed Phase II testing in HD.

Brigham and Women's Hospital of the Harvard Medical School has filed a patent application for the inhibitors of cytochrome $\mathrm{C}$ release. The compounds are available for licensing worldwide, said Friedlander.

\section{Transcription prescription}

In a paper in the Proceedings of the National Academy of Sciences, Elizabeth Thomas and colleagues at Scripps used a new HDAC inhibitor, HDACi $4 \mathrm{~b}$, to correct the transcriptional dysregulation associated with HD.

Her team showed that HDACi $4 \mathrm{~b}$ was not cytotoxic in vitro, and it caused a twofold increase in acetylation of H4, which opens the chromatin structure to facilitate transcription. In a mouse model of $\mathrm{HD}$, the compound improved motor performance and coat appearance compared with the effects of vehicle controls.

Compared with the control group, mice receiving HDACi $4 \mathrm{~b}$ also lost less body and brain weight.

Thomas, assistant professor in the Department of Molecular Biology at Scripps, told SciBX that transcriptional dysregulation is one of the earliest pathological mechanisms in HD. Even though the exact pathway of disease pathology has not been confirmed, she said it is thought that the defects in gene expression precede mitochondrial dysfunction and therefore inhibition of HDAC might act upstream of inhibitors of cytochrome $\mathrm{C}$ release.

"Because transcriptional dysregulation is very likely a core pathogenic mechanism of disease, our compounds should also help relieve the downstream pathologies," said Thomas.

"We've looked at the effects of the compounds at the beginning of symptoms and are now looking at the effects of administration before symptom onset. If we find that it works better before symptoms occur, genetic screening and early treatment could be more effective ways to treat the disease," she noted.

Thomas also said her lab is working to resolve toxicity issues associated with HDAC inhibitors. The first marketed HDAC inhibitor, Zolinza vorinostat (suberoylanilide hydroxamic acid) from Merck \& Co. Inc., is associated with side effects including nausea, vomiting and diarrhea, tiredness, upper respiratory infection, deep vein thrombosis and pulmonary embolus. The pan-HDAC inhibitor is approved to treat cutaneous T cell lymphoma (CTCL).

"The toxicity profile would be unacceptable" in HD patients, said Pacifici. "Pan inhibitors are not the way to go."

Thomas said that Scripps has filed a patent for HDACi $4 \mathrm{~b}$ and other similar compounds. Repligen Corp. holds rights to the patent and is conducting preclinical work to determine ideal doses and metabolic effects of the compounds.

"More than a dozen HDAC enzymes have been identified, and we are targeting members of class 1," said Repligen president and CEO Walter Herlihy. "The compounds have high inhibitory potential for HDAC3 specifically."

He added that "we are analyzing toxicity and pharmacology, which includes bioavailability and the ability of the compounds to cross the blood-brain barrier."

Herlihy told SciBX that Repligen hopes to identify a pharmaceutical 


\section{TARGETS \& MECHANISMS}

candidate by the end of this year and to start Phase I testing in 2009, pursuing the initial indication of Friedreich's ataxia (FA).

\section{Combinations}

Although the treatment strategies presented by the Harvard and Scripps teams are different, they are not necessarily competing approaches. Indeed, companies and institutions contacted by SciBX hope both strategies could fit into the treatment space.

"I think a cocktail-type approach will be the best answer for this disease, as it is for cancer and HIV," said Friedlander.

Tsao-Nivaggioli agreed. "Probably in the end it will be combination treatment. We will still need to rely on some symptomatic treatments and some to slow disease progression," she said.

In addition to symptomatic treatments, the HDAC- and cytochrome $\mathrm{C}$-inhibiting approaches could be coupled with therapies that aim to fix the source of the disease: the mutated protein.

Rubinsztein said exclusively targeting downstream effects such as neuron damage might not address all of the pathogenic mechanisms of the disease, and patients might see little efficacy. "It would be more appealing to remove the toxic protein itself," he said.

Ideally, an HD therapy would correct the mutant gene. However, said Rubinsztein, "one would have to chop out the extra repeats and would have to do it in a high enough proportion of relevant cells in the brain. There might be a way to do it in a limited number of cells, but this poses quite a challenge."

He concluded: "The next best thing would be to remove the toxic protein."

Rubinsztein's lab is currently trying to enhance degradation of the mutated protein.
The CHDI foundation and Isis Pharmaceuticals Inc. are trying to lower mutant HTT protein expression with antisense oligonucleotides under an agreement that was expanded last year.

"One important thing to consider is that rodent studies have proven that htt is an essential protein and its knockdown is embryonically lethal. We now need to determine how much can be knocked down for therapeutic benefit and how much would be detrimental," Pacifici said.

\section{REFERENCES}

1. Wang, X. et al. J. Neurosci.; published online Sept. 17, 2008; doi:10.1523/JNEUROSCI.1867-08.2008

Contact: Robert Friedlander, Brigham and Women's Hospital, Harvard Medical School, Boston, Mass. e-mail: rfriedlander@rics.bwh.harvard.edu

2. Thomas, E. et al. Proc. Natl. Acad. Sci. USA; published online Sept. 15, 2008; doi:10.1073/pnas.0804249105 Contact: Elizabeth Thomas, The Scripps Research Institute, La Jolla, Calif. e-mail: bthomas@scripps.edu

3. Schilling, B. et al. J. Biol. Chem. 281, 23686-23697 (2006)

4. Berman, S. \& Greenamyre, J. Curr. Neurol. Neurosci. Rep. 6, 281-286 (2006)

COMPANIES AND INSTITUTIONS MENTIONED

Avicena Group Inc. (OTCBB:AVGO), Palo Alto, Calif. Brigham and Women's Hospital, Boston, Mass. CHDI Foundation Inc., New York, N.Y. Harvard Medical School, Boston, Mass. Isis Pharmaceuticals Inc. (NASDAQ:ISIS), Carlsbad, Calif. Mental Health Research Institute of Victoria, Melbourne, Australia Merck \& Co. Inc. (NYSE:MRK), Whitehouse Station, N.J. Prana Biotechnology Ltd. (ASX:PBT; NASDAQ:PRAN), Melbourne, Australia

Repligen Corp. (NASDAQ:RGEN), Waltham, Mass.

The Scripps Research Institute, La Jolla, Calif.

University of Cambridge, Cambridge, U.K 